der Giessen, Heleen de Greef, Herman Grooten, Jessica Harmsen, Lex Jongsma, Bert Kieboom, Henk de Kleijnen, Tim Krabbé, Nico Kuijf, Gert Ligterink, Gunther Loewenthal, Hennie Maliangkay, Max Pam, Hebert Perez Garcia, Dieter Steinwender, Klaas Steyn, Ed Voortmeijer, Martin Voorn, Peewee van Voorthuijsen, Sylvia de Vries and Wim Wolthuis.

The list of computers reads: Hiarcs, The King AEGON, Chess Genius 2, NIMZO-Guernica, Hitech, Gideon 2.0, Pandix, Quest, Saitek Sparc, Fritz2, Kallisto, M_Chess Pro, Bobby II, Mirage, Chessmaster 4000, Socrates exp., Milobarus, Ecume, Now, R30, Mephisto Genius, R40, Dappet, Mephisto Risc wk., Zarkov3, Mephisto Berlin, Saitek Risc 2500, Saitek Brute Force, Cumulus, L-Chess, Complete Chess System X, Gandalf, Nightmare, Check Check, Ananse, Schach 3.0 and Goldbar.

On all tournament days (April 27-29, May 2-4) playing times will be from 7:30 to 11:30 p.m., local time at the AEGON Headquarters, Mariahoeveplein 50, The Hague, The Netherlands. For details, please contact me, by snail mail at Valkenboskade 607,2563 JE The Hague, by telephone at $+31-70-4643729$.

\title{
THE ACM'S 24 ${ }^{\text {th }}$ INTERNATIONAL COMPUTER-CHESS CHAMPIONSHIP
}

\section{A Special Event at the $6^{\text {th }}$ Symposium on Parallel Algorithms and Architecture}

\author{
Grand Hotel \\ Cape May, New Jersey
}

June 25-27, 1994

Monty Newborn

The ACM's $24^{\text {th }}$ International Computer-Chess Championship will be held as a special event at the $6^{\text {th }}$ Symposion on Parallel Algorithms and Architecture, June 25-27, 1994 in Cape May, New Jersey. The fiveround Swiss-style event will be played at a rate of 40 moves in the first two hours and 20 moves every hour thereafter. Two rounds are scheduled on Saturday, two on Sunday, and the final round will take place on Monday. The field will be limited to twelve teams. With the level of play of the top programs at the grandmaster level, the event promises to be one more important milestone in the history of the rapid progress of chess programming. Several of the participants are expected to use large multiprocessing systems, while others will use high-speed personal computers. So far, the following programs have entered the tournament: Deep Blue, Zarkov, Startech (on Connection Machine) M_Chess, Socrates (or equivalent), Cray Blitz and Now. For more information or to enter, contact Professor Monty Newborn, School of Computer Science, McGill University, 3480 University Street, Montreal, Quebec, Canada H3A 2A7. (Tel. +1-514-398-7079 and email address: newborn@cs.mcgill.ca). Entries close on June 2, 1994.

\section{THE QMW'S UNIFORM-PLATFORM COMPUTER-CHESS TOURNAMENT}

\author{
QMW, London \\ August 1-8, 1994
}

Don Beal

QMW will be running the uniform-platform tournament for the third time in 1994. The uniform-platform concept gives every program an identical computer to run on, and provides a forum in which programs can compete to be champion program, with hardware resources equalised.

In addition, the tournament is run with automatic play. Programs do not require human operators. This means programmers need not be present, thus saving time and money. Participants and spectators, of course, are still welcome.

The organisers provide the computers. The minimum configuration will be $486 \mathrm{DX} 40$ PCs with $8 \mathrm{MB}$ RAM running DOS 6. If available, faster machines may be used (e.g., Pentiums). 